Note

\title{
Use of Microwave-assisted Hydrodistillation to Extract the Essential Oils from
}

\section{Satureja hortensis and Satureja montana}

\author{
Shila Rezvanpanah, Karamatollah RezaeI*, Seyyed Hadi Razavi, Sohrab Moini \\ Department of Food Science and Engineering, Faculty of Biosystem Engineering, The University of Tehran, Karaj, Iran, Postal Code: \\ 31587-77871
}

Received October 31, 2007; Accepted February 8, 2008

Microwave-assisted hydrodistillation (MAHD) has recently been attended for the extraction of essential oils from medicinal plants/herbs. In this study, MAHD was investigated for the extraction of essential oils from two genotypes of savory (Satureja hortensis, so-called summer savory, and Satureja montana, socalled winter savory). Three levels of microwave power $(220,440$ and $660 \mathrm{~W})$ were selected for the extraction. MAHD resulted in a shorter extraction time compared to that in HD. Total extraction times at $660 \mathrm{~W}$ microwave power was $180 \mathrm{~min}$ for $S$. hortensis and $90 \mathrm{~min}$ for $S$. montana. The extraction yield obtained by MAHD was almost equal to that obtained by $\mathrm{HD}(3.1 \%$, w/w, for $S$. hortensis and $0.7 \%$ for $S$. Montana). Extraction was more efficient at higher power levels.

Keywords: essential oils, microwave-assisted hydrodistillation, Satureja hortensis, Satureja montana, savory

\section{Introduction}

The use of herbs and plants in food industry has a long history. The diversity among the components of the plants has resulted in their use in many applications including in flavors and fragrances as well as in medicine. Essential oils are among the secondary metabolites produced within the various organs of medicinal herbs/plants. They are complex mixtures of volatile compounds such as terpenes (mostly monoterpenes and sesquiterpenes), phenolics and alcohols (Lucchesi et al., 2004). The conventional method for the extraction of essential oils is hydrodistillation (HD), in which the essential oils are evaporated by heating a mixture of water and plant materials followed by the liquefaction of the vapors in a condenser. However, this method suffers from several disadvantages including losses in the volatile compounds, long extraction time and degradation of some components through thermal and/or hydrolytic effects (Khajeh et al., 2004; Lucchesi et al., 2004). Because of these shortcomings, newer approaches such as microwave-assisted extraction (MAE,) with or without the use of a solvent, have been developed. MAE, for example, has been applied for the

*To whom correspondence should be addressed.

Email: krezaee@ut.ac.ir extraction of cocaine and benzoylecgonine from coca leaves by using both polar and nonpolar solvents (Brachet et al., 2002). MAE has also been investigated for the extraction of essential oils from several herbs including artemisia (Hao et al., 2002), caraway seeds (Chemat et al., 2005), orange peel (Ferhat et al., 2006), lavender (Chemat et al., 2006), and cardamom (Lucchesi et al., 2007). Another extraction method in this area is microwave assisted hydrodistillation (MAHD,) which is an advanced hydrodistillation method based on the use of a microwave oven. This technique has recently been investigated in the extraction of volatile secondary metabolites from Lippia Alba (Stashenko et al., 2004a) and Xylopia aromatica (Stashenko et al., 2004b). The efficiency of MAHD is strongly dependent on the dielectric constant of water and the matrix (Brachet et al., 2002). MAHD causes the rapid delivery of energy to the total volume of solvent/ sample leading to a rapid rise in the temperature. Heat is originated through the molecular motions within the polar components or ionic species (Brachet et al., 2002). That is, the rise in temperature within the plant cells is similar to that occurring outside the cells. Once the pressure within the glands reaches above certain level, the external cell walls break apart and as a consequence the essential oils are released to the environment (Chemat et al., 2005). From this 
point on, the essential oils are carried away by water vapor, liquefied in the condenser on the top of the main apparatus and collected in the receiving flask (Chemat et al., 2006). Because of different densities and also due to their immiscibilities, water and essential oils are separated from each other and the excess water is refluxed to the extraction vessel (Chemat et al., 2006).

Savory, from the Labiatae family, is among the medicinal plants having relatively higher level of essential oils when compared to other herbs. Carvacrol, $\gamma$-terpinene, $\rho$-cymene and thymol are among the most important bioactive components present in the essential oils of savory (Sefidkon et al., 2006). While having strong flavors, these components also posses certain levels of antimicrobial and medicinal properties. Extraction of essential oils from savory has been reported using HD (Sefidkon and Jamzad, 2005; Sefidkon et al., 2006) and supercritical fluid extraction (Esquivel et al., 1999). However, no studies have been reported in the literature to apply MAHD for the extraction of essential oils from savory. Therefore, the objectives of this study were to extract the essential oils from two genotypes of savory, Satureja hortensis (summer savory) and Satureja montana (winter savory) using MAHD and to compare the yields and the extraction kinetics in this method with those of HD.

\section{Materials and Methods}

Plant materials $S$. hortensis was provided from the farms of Industrial Center for Plant Pesticides and Fertilizers (Karaj, Iran). S. montana was harvested from Maraghe, Azarbayejan, Iran. Both plants were cleaned and dried in a dark room at $25^{\circ} \mathrm{C}$. The initial moisture contents of $S$. hortensis and $S$. montana at the time of extraction were 8.6 and $9.0 \%$ (w/w), respectively.

Hydrodistillation A "water to plant" ratio of 20:1 (w/w) was considered for HD. Sixty g S. montana was mixed with 1.2 L of distilled water and extraction was performed using a Clevenger-type apparatus for a total length of $4 \mathrm{~h}$, after which no more essential oils were extracted. The essential oils were collected, dried over anhydrous sodium sulphate and stored at $4{ }^{\circ} \mathrm{C}$ until used. For S. hortensis, $30 \mathrm{~g}$ plant materials were mixed with $600 \mathrm{~mL}$ of distilled water and extraction was performed in a similar approach as the one explained for S. montana. For each plant, extraction was repeated 3 times.

Microwave-assisted hydrodistillation MAHD was performed at atmospheric pressure with a microwave frequency of $2450 \mathrm{MHz}$ using a household microwave oven (Panasonic Corp., Japan, model NN-S674 MF) with a maximum output power of $1100 \mathrm{~W}$ and inner dimensions of $22.5 \mathrm{~cm} \times 37.5$ $\mathrm{cm} \times 38.6 \mathrm{~cm}$ equipped with a flask and a condenser.
Water/plant ratio of 20:1 (w/w) was also considered with MAHD and $60 \mathrm{~g}$ of $S$. montana and $30 \mathrm{~g}$ of $S$. hortensis were extracted using three different power levels of 220, 440 and $660 \mathrm{~W}$. The essential oils were collected, dried over anhydrous sodium sulphate and then stored at $4^{\circ} \mathrm{C}$ until used. Extraction was performed 3 times for each plant.

\section{Results and Discussion}

Effect of extraction time Times needed to reach the extraction temperature (so-called induction times) are shown on Figure 1a for $S$. hortensis and Figure $1 \mathrm{~b}$ for $S$. montana. For both methods, the extraction started at the boiling point of water at the ambient conditions. For MAHD (at $660 \mathrm{~W}$ ), the extraction started much earlier than that in HD. With HD, induction time was $14 \mathrm{~min}$ for $S$. hortensis and $30 \mathrm{~min}$ for S. montana. However, with MAHD at $660 \mathrm{~W}$, the induction time was $6 \mathrm{~min}$ for $S$. hortensis and $12 \mathrm{~min}$ for $S$. Montana. Such results can be attributed to the more powerful effect of microwaves on water, a solvent with a high dielectric constant. However, once the microwave power was reduced to $220 \mathrm{~W}$, the induction time with MAHD was longer than that in HD (Figs. 1a and 1b). This is related to the low density of
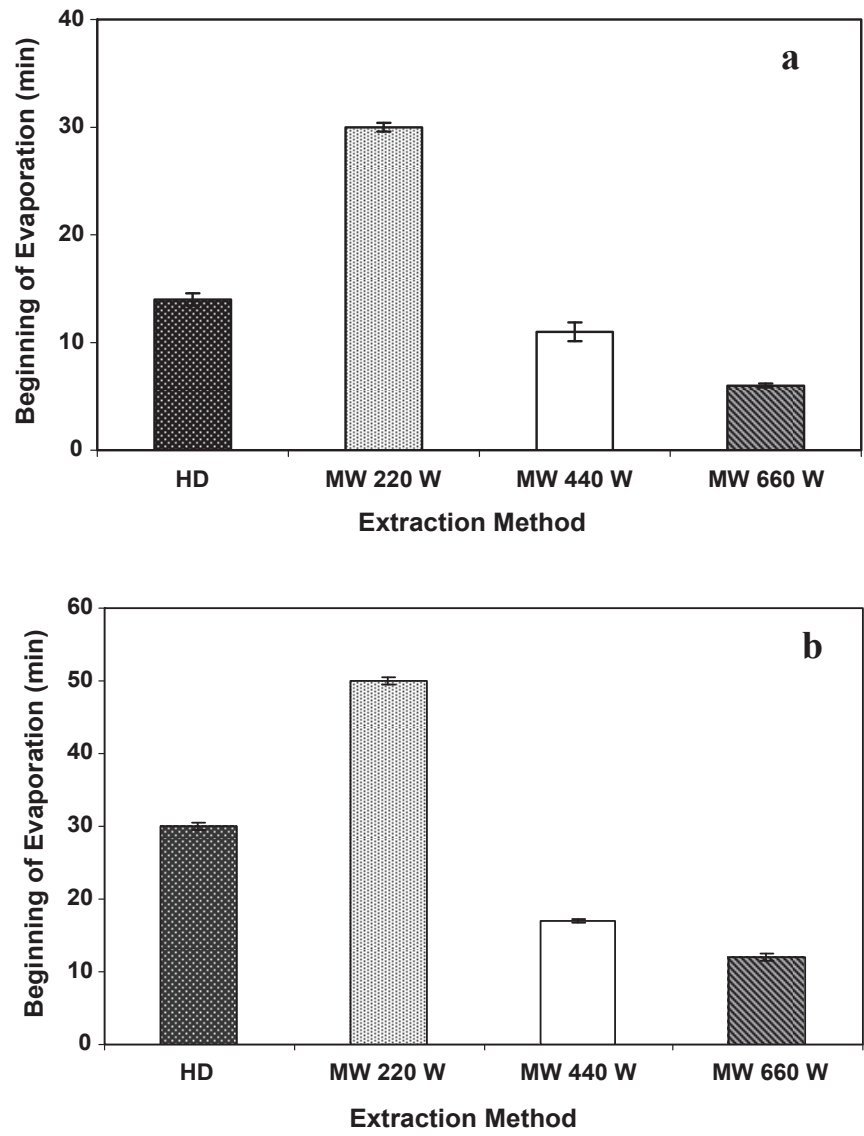

Fig. 1. Effect of microwave (MW) power on the starting time of extraction in S. hortensis (a) and S. montana (b). Hydrodistillation (HD) was used as a reference method $(n=3)$. 


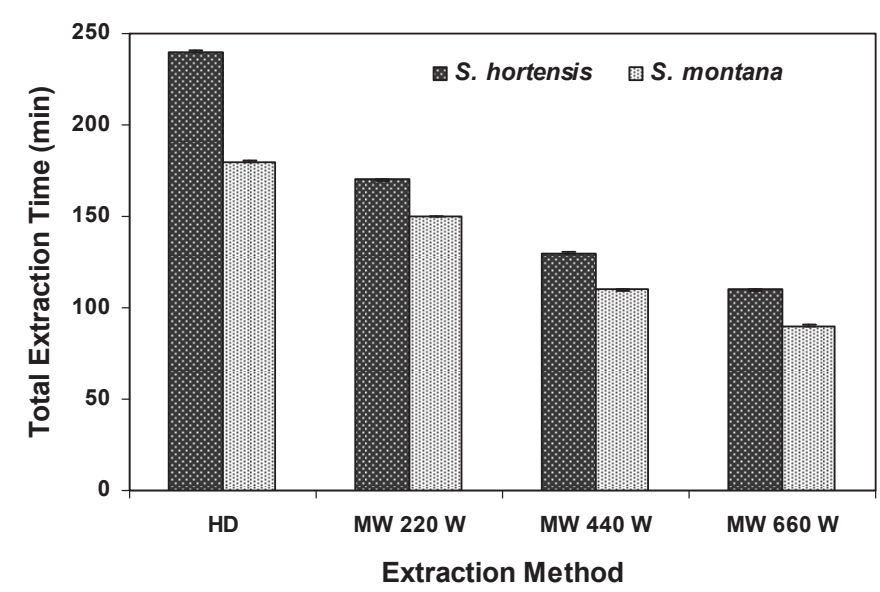

Fig. 2. Effect of microwave (MW) power on the extraction time of essential oils from $S$. hortensis and $S$. montana. Hydrodistillation (HD) was used as a reference method $(n=3)$.

waves at this power level.

Total times needed to fully recover the essential oils from the two plants at different power levels are shown on Figure 2. MAHD needed shorter times than HD. Such effect is clearer when microwave power is increased to higher levels. Total extraction time needed for HD was 240 min for S. hortensis and $180 \mathrm{~min}$ for S. montana. These results are in agreement with those of Ferhat et al. (2006) and Chemat et al. (2006) in the extraction of essential oils from orange peels and lavender, respectively. It can also be concluded that by increasing microwave power from 220 to $660 \mathrm{~W}$, the induction time for evaporation and total time for the extraction decrease (Figs. 1 and 2). According to Chen and Spiro (1995) and Lucchesi et al. (2007), at higher power levels, the microwaves (i.e., the radiations) can be absorbed by water more intensively and as a result the disruption rate of cellular texture and release of essential oils also increase. Using scanning electron microscopy, Chen and Spiro (1995) and Lucchesi et al. (2007) also reported that cells undergone MAE resulted in faster rupture than those undergone the conventional extraction. When studying two genotypes of thyme using MAHD, Golmakani and Rezaei (2008a,b) reported that chemical compositions of the oils extracted with MAHD were similar to those obtained by the conventional HD method.

Extraction yield The changes in the extraction yield of essential oils by HD and MAHD are shown on Figures 3a (S. hortensis) and 3b (S. montana). In both cases, the extraction yield increased with time. When considering the extraction patterns of each plant separately, both MAHD and HD resulted in similar yields after the extraction was over. Total yield of extraction was $3.12 \%(\mathrm{w} / \mathrm{w})$ for $S$. hortensis and $0.7 \%(\mathrm{w} / \mathrm{w})$ for $S$. montana. In the extraction of essential oils from Origanum glandulosum, Bendahou et al. (2008)
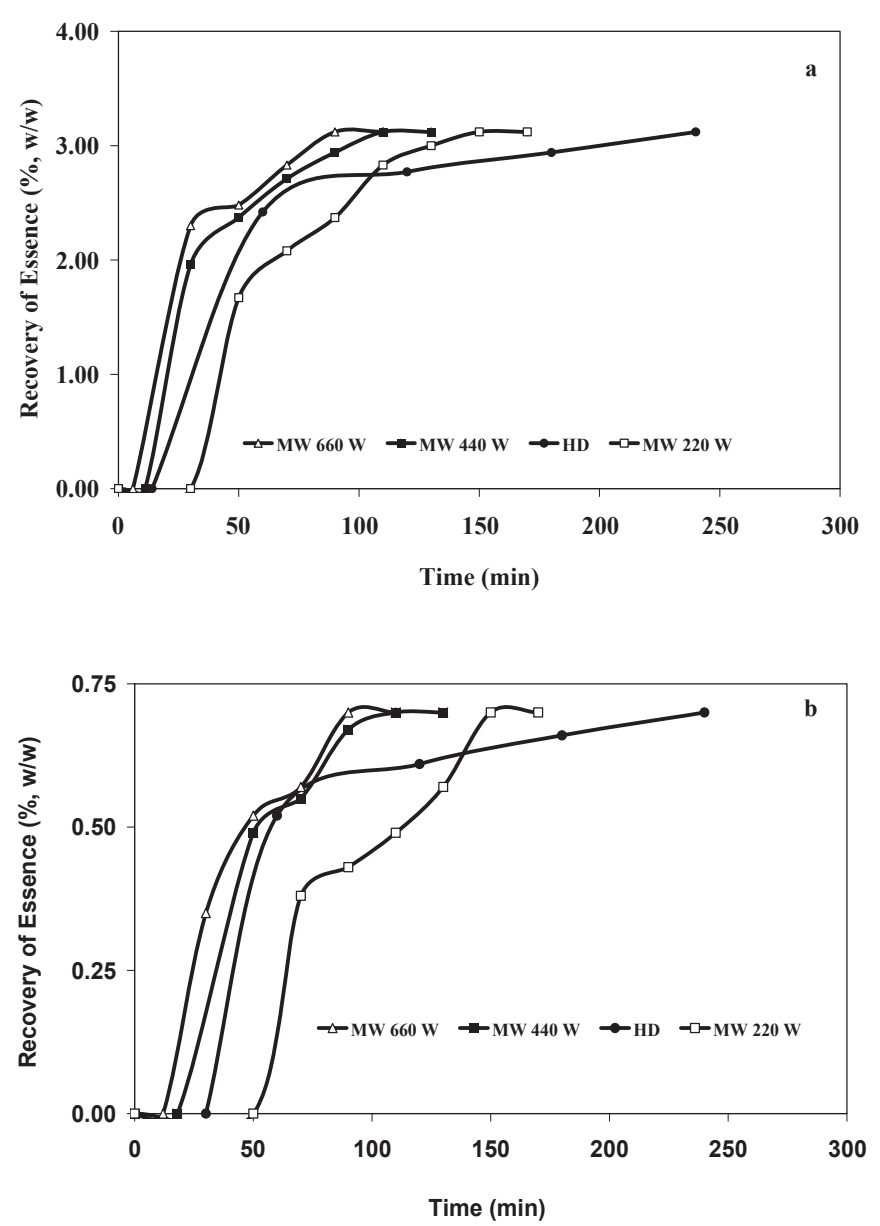

Fig. 3. Extraction yield of essential oils from S. hortensis (a) and S. montana (b) by Hydrodistillation (HD) and microwave-assisted hydrodistillation (MAHD) $(\mathrm{n}=3)$.

reported that the extraction yield by HD was greater than that by MAE. This can be related to the differences in the properties of the solvents used in MAE and that of water, which is used in HD. Bendahou et al. (2008) used hexane as solvent, which has lower solvent power compared to water used in HD. According to Figures $3 a$ and $3 b$, at a given time, in the early stages of extraction, extraction yield was greater with MAHD than with HD. For example, the extraction yield for S. hortensis at $50 \mathrm{~min}$ was $1.67 \%(\mathrm{w} / \mathrm{w})$ with $\mathrm{HD}$ and 2.00 , 2.37 and $2.48 \%$, with MAHD at 220, 440 and $660 \mathrm{~W}$, respectively. This is in agreement with the findings of Lucchesi et al. (2004) and Chemat et al. (2006) that MAE of essential oils from cumin, star anise and lavender needed shorter times than did HD. Indeed, water with a high dielectric constant absorb the radiation from the microwaves resulting in a rise in the temperature more rapidly than that in HD. Higher temperature causes an easier degradation of plant cells and consequently a shorter extraction time can be achieved (Käufmann et al., 2001). This effect is more evident at higher power levels. 


\section{Conclusions}

Extraction with MAHD was more efficient than that by the conventional HD using a Clevenger-type apparatus. However, both HD and MAHD resulted in similar amounts of extracts if enough time were allowed with HD. Therefore, in order to reduce the extraction time MAHD can be used for the extraction of metabolites from the herbs instead of conventional HD. There is a need to investigate the effect of microwave radiation on the structure of the components of essential oils especially those responsible for the flavor and fragrance from the plants.

Acknowledgement This work has been partially funded by a grant provided by "the Council for Research at the Campus of Agriculture and Natural Resources of the University of Tehran" and "Research Council of the University of Tehran." Gratitude is expressed to "Industrial Center for Plant Pesticides and Fertilizers" (Karaj, Iran) for providing the plant materials and also for purchasing part of the equipment. The authors would like to thank Mrs. Nahal Bashiri Hashemi and Mr. Mohammad-Taghi Golmakani for their technical assistance.

\section{References}

Brachet A., Christen P., Veuthey J. L. (2002). Focused microwaveassisted extraction of cocaine and benzoylecgonine from coca leaves. Phytochemical Analysis, 13, 162-169.

Bendahou M., Muselli A., Grignon-Dubois M., Benyoucef M., Desjobert J. M., Bernardini A. F., Costa J. (2008). Antimicrobial activity and chemical composition of Origanum glandulosum Desf. essential oil and extract obtained by microwave extraction: Comparison with hydrodistillation. Food Chemistry, 106, 132-139.

Chemat S., Ait-Amar H., Lagha A., Esveld D. C. (2005). Microwave-assisted extraction kinetics of terpens from caraway seeds. Chemical Engineering and Processing, 44, 1320-1326.

Chemat F., Lucchesi M. E., Smadja J., Favretto L., Colnaghi G., Visinoni F. (2006). Micowave accelerated steam distillation of essential oil from lavender: A rapid, clean and environmentally friendly approach. Analytica Chimica Acta, 555, 157-160.

Chen S. S., Spiro M. (1995). Kinetics of microwave extraction of rosemary leaves in hexane, ethanol and a hexane + ethanol mixture. Flavor and Fragrance Journal, 10, 101-112.

Esquivel M. M., Ribeiro M. A., Bernardo-Gil M. G. (1999). Supercritical extraction of savory oil: study of antioxidant activity and extract characterization. Journal of Supercritical Fluids, 14, 129-138.
Ferhat M. A., Meklati B. Y., Smadja J., Chemat F. (2006). An improved microwave Clevenger apparatus for distillation of essential oils from orange peel. Journal of Chromatography A, 1112, 121-126.

Golmakani M., Rezaei K. (2008a). Comparison of microwaveassisted hydrodistillation with the traditional hydrodistillation method in the extraction of essential oils from Thymus vulgaris $\mathrm{L}$. Food Chemistry, 109, 925-930.

Golmakani M., Rezaei K. (2008b). Microwave-assisted hydrodistillation of essential oil from Zataria multiflora Boiss. European Journal of Lipid Science and Technology, 110, 448-454.

Hao J., Han W., Huang Sh., Xue B., Deng X. (2002). Microwaveassisted extraction of artemisin from Artemisia annua L. Separation and Purification Technology, 28, 191-196.

Käufmann B., Christen P., Veuthey J. L. (2001). Parameters affecting microwave-assisted extraction of withanolids. Phytochemical Analysis, 12, 327-331.

Khajeh M., Yamini Y., Sefidkon F., Bahramifar N. (2004). Comparison of essential oil composition of Carum copticum obtained by supercritical carbon dioxide extraction and hydrodistillation methods. Food Chemistry, 86, 587-591.

Lucchesi M. E., Chemat F., Smadja J. (2004). Original solvent free microwave extraction of essential oils from spices. Flavor and Fragrance Journal, 19, 134-138.

Lucchesi M. E., Chemat F., Smadja J. (2004). Solvent-free microwave extraction of essential oil from aromatic herbs: comparison with conventional hydrodistillation. Journal of Chromatography A, 1043, 323-327.

Lucchesi M. E., Smadja J., Bradshaw S., Louw W., Chemat F. (2007). Solvent free microwave extraction of Elletaria cardamomum L.: A multivariate study of a new technique for the extraction of essential oil. Journal of Food Engineering, 79, 1079-1086. Sefidkon F., Abbasi Kh., Bakhshi Gh. (2006). Influence of drying and extraction methods on yield and chemical composition of the essential oil of Satureja hortensis. Food Chemistry, 99, 19-23.

Sefidkon F., Jamzad Z. (2005). Chemical composition of the essential oil of three Iranian Satureja species (S. mutica, S. macrantha and S. intermedia). Food Chemistry, 91, 1-4.

Stashenko E. E., Jaramillo B. E., Martínez J. R. (2004b). Analysis of volatile secondary metabolites from Colombian Xylopia aromatica (Lamarck) by different extraction and headspace methods and gas chromatography. Journal of Chromatography A, $\mathbf{1 0 2 5}$, 105-113.

Stashenko E. E., Jaramillo B. E., Martínez J. R. (2004a). Comparison of different extraction methods for the analysis of volatile secondary metabolites of Lippia alba (Mill.) N. E. Brown, grown in Colombia, and evaluation of its in vitro antioxidant activity. Journal of Chromatography A, 1025, 93-103. 